This item was submitted to Loughborough's Research Repository by the author.

Items in Figshare are protected by copyright, with all rights reserved, unless otherwise indicated.

\title{
The effect of shock loads on SAF bioreactors for sewage treatment works
}

PLEASE CITE THE PUBLISHED VERSION

http://dx.doi.org/10.1016/j.cej.2010.10.005

\section{PUBLISHER}

(c) Elsevier

VERSION

AM (Accepted Manuscript)

LICENCE

CC BY-NC-ND 4.0

\section{REPOSITORY RECORD}

Hu, Bibo, Andrew D. Wheatley, Vera Ishtchenko, and Katherine Huddersman. 2019. "The Effect of Shock Loads on SAF Bioreactors for Sewage Treatment Works". figshare. https://hdl.handle.net/2134/11291. 
This item was submitted to Loughborough's Institutional Repository (https://dspace.lboro.ac.uk/) by the author and is made available under the following Creative Commons Licence conditions.

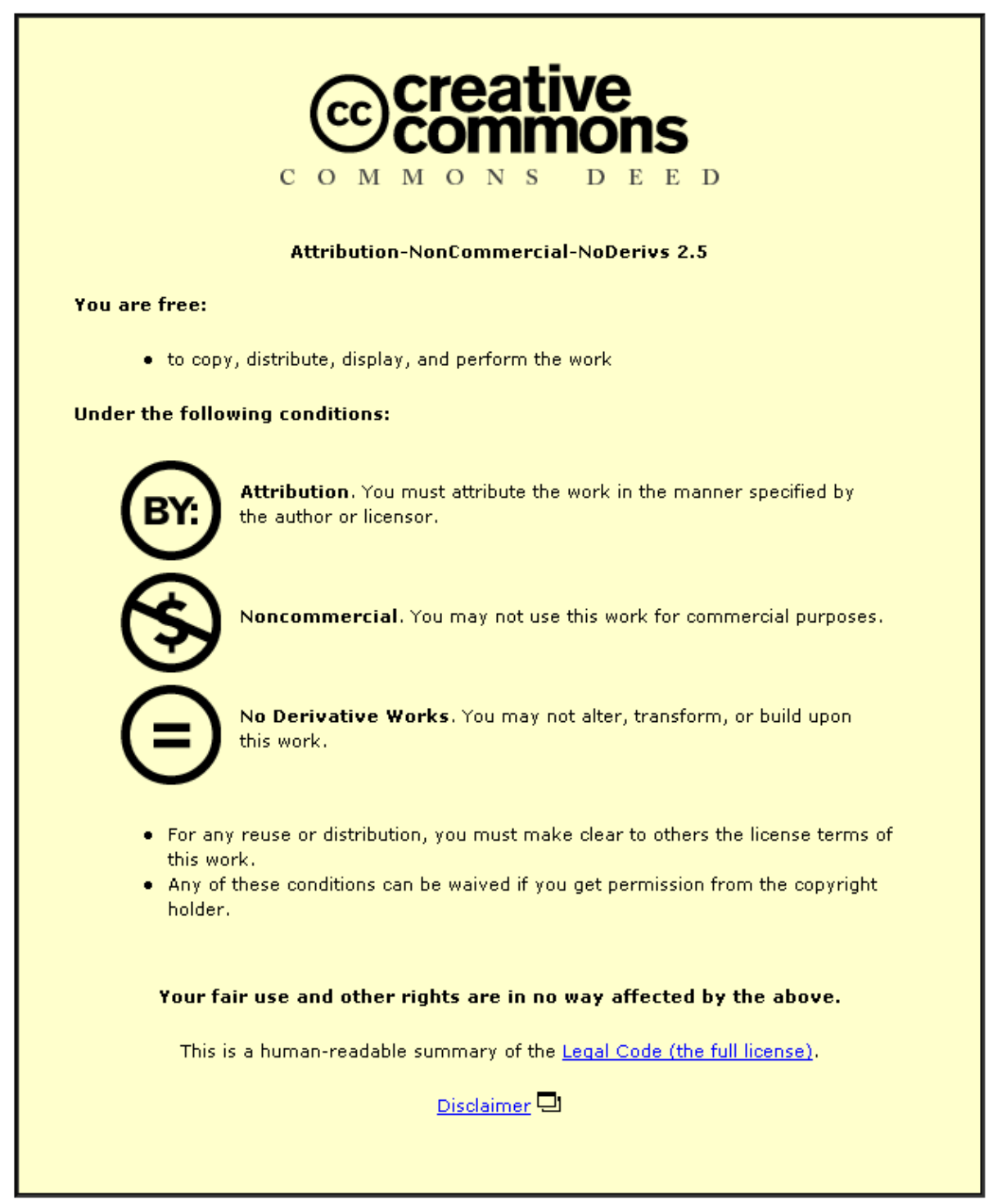

For the full text of this licence, please go to: http://creativecommons.org/licenses/by-nc-nd/2.5/ 


\title{
The Effect of Shock Loads on SAF Bioreactors for
}

\section{Sewage Treatment Works}

Bibo $\mathrm{Hu}^{\mathrm{a}}$, Andrew Wheatley ${ }^{\mathrm{a}}$, Vera Ishtchenko ${ }^{\mathrm{b}}$ and Katherine Huddersman ${ }^{\mathrm{b} *}$

${ }^{a}$ Department of Civil and Building Engineering, Loughborough University, Loughborough, UK

${ }^{b}$ Leicester School of Pharmacy, Faculty of Health \& Life Sciences, De Montfort University,UK

*Corresponding author. Faculty of Health \& Life Sciences, De Montfort University, UK. Tel.: +44

(0)1162 577134; email addresses: huddzeo1@dmu.ac.uk (Katherine Huddersman);

A.D.Wheatley@lboro.ac.uk (Andrew Wheatley), vvi@dmu.ac.uk (Vera Ishtchenko).

\begin{abstract}
The present study compares the influence of organic and hydraulic shock loadings on the performance of submerged aerated filters (SAFs) packed with wool, as a novel media and Kaldnes rings media in terms of total organic carbon (TOC), suspended solids (SS) and ammonia removal. The SAFs continued to achieve an average of more than $95 \%$ TOC removal, $100 \%$ of SS removal efficiency and $99.8 \%$ ammonia removal even when subject to shock loads. The ammonia removal was more sensitive than the other parameters, which was attributed to the slow growth of nitrifying bacteria, which are poor competitors for space and substrate. SAF packed with wool had a better capacity to overcome hydraulic shock than the SAF with Kaldnes, attributed to the better filtration properties, however, both SAFs exhibited rapid return to normal operation conditions after both short and longer shock loading. On doubling the organic load, the reactors responded differently, rapidly coping with the shock but were less stable. The longer-term organic shock loading caused a greater disturbance until sufficient biomass had grown to compensate, suggesting that mass transfer is less important than growth kinetics.
\end{abstract}

Keywords: submerged aerated filter, novel wool media, hydrodynamics, residence time distribution, biomass, wastewater treatment 


\section{Introduction}

Tighter controls on discharge limits of wastewater treatment systems have resulted in more elaborate solutions than conventional biological treatment process [1]. The development of fixed biomass reactors has ensured significant advances in the knowledge and application of this type of treatment. Compared to conventional units, fixed film bioreactors perform efficiently at higher organic loading rates due to a more effective biomass retention in the reaction zone resulting in higher cellular retention times [2]. The steady state performance of bioreactors is linked to their biomass concentrations.

Potential harmful environmental changes are often caused by shock loads [3] because of the variable nature of industrial and sewage wastes. Reactor stability to shock loading is therefore one of the most important design aspects of biological treatment systems. The sudden change of influent concentration, or organic shock loading, is able to eventually destabilise the performance of treatment systems. The degree of deterioration in performance depends on the duration and magnitude of the shock and the rate of adaptability of the microbes.

During organic shocks the major factor limiting the overall reaction rate appears to be the kinetics of the biomass. The effect of higher biomass concentrations in aerobic reactors usually enhances their stability rather than improves COD removal. In contrast, during hydraulic shocks the rate of mass transfer of substrate into the biomass aggregates is likely to be the limiting factor [4].

Shock loads occur be in two ways, which are, either as a short-term transient which only lasts a few hours, or as a longer-term change of days to weeks before reversion back to the original operating conditions. During short-term shock, the degree of deterioration change will depends on the duration and magnitude of the shock and the rate of adaptability of the microorganisms. The literature has evidenced that bioreactors can handle short-term and long-term shock loads and sometimes even tolerate triple organic loading rate (OLR) [5-8]. The longer-term shock should lead to a new "steady state" which is identical to the original operating conditions in terms of TOC removal and other parameters [4]. The time to achieve steady state is proportional to biomass concentration, i.e. the higher biomass concentration designed for in the reactor, the more stability for treatment.

Considering the high solid retention time for slow growing biomass and the high biomass concentrations, the ability of the SAF when packed with wool fleece to treat shock loads was studied in this work. 


\section{Experimental}

\subsection{Media}

Experiments were studied with two types of media: wool ${ }^{\circledR}$ and Kaldnes ${ }^{\circledR}$. Wool ${ }^{\circledR}$ was a top wool with fibre diameter of $20 \mu \mathrm{m}$ produced by the standard method of industrial alkaline scouring to remove wool grease. This is the most common grade of wool and used in textiles and carpets. The Kaldnes was a commercial polyethylene media, diameter $9 \mathrm{~mm}$, length $7.5 \mathrm{~mm}$, specific surface area $500 \mathrm{~m}^{2} / \mathrm{m}^{3}$, density $0.95 \mathrm{~g} / \mathrm{cm}^{3}$, voidage $75 \%$.

\subsection{Design and Construction of SAF}

Two identical lab-scale SAFs (Figure 1) were made for this work in the Department workshop at Loughborough. They were designed and operated to simulate a scaled down version of the pilot unit described by Cannon et al [9].

The filters were fabricated out of $140 \mathrm{~mm}$ (internal diameter) polypropylene columns. The total height of each reactor was $610 \mathrm{~mm}$ and the empty bed liquid volume of the filter was $6.93 \mathrm{~L}$. One SAF was packed with wool fleece the other with Kaldnes. The height of the filter area was $380 \mathrm{~mm}$ above a grid in both reactors, which meant that $70 \%$ volume of the filter was packed with media. The SAFs were upflow and fed by peristaltic pumps. The inlet was located below a mesh with a diameter of $15 \mathrm{~mm}$, and the mesh was positioned $130 \mathrm{~mm}$ above the bottom for supporting the media and separating the filter into two main areas: filter area and sludge area. The height of the sludge area was $50 \mathrm{~mm}$ and the sludge was discharged through a pipe (15 mm diameter) fixed under the filter. The aeration and inlet were both above the sludge area.

Air was also supplied above the sludge area of the filter. The diameter of the aeration loop was $120 \mathrm{~mm}$, with air holes evenly located around circular aeration loop. The The outlet (10 mm diameter) is located at the centre of reactor, $35 \mathrm{~mm}$ below the top of filter.

Fig 1. - Diagram of the SAF system. 


\subsection{Synthetic wastewater}

To investigate pollutant removal by the reactor, the lab-scale SAFs were fed with synthetic sewage to represent settled sewage, i.e. the primary effluent. The synthetic sewage has uniform characteristics with no risk of toxic or industrial components. The composition of the synthetic sewage was based on that originally used by Phanapavudihikul to study laboratory and pilot-scale effects of temperature on activated sludge [10]. The constituents (Sigma-Aldrich) of the synthetic sewage together with their concentrations are given in Table 1. The influent to the filters was prepared every two days to avoid significant ageing. The influent was prepared by dissolving the concentrate recipe in hot water followed by dilution with tap water in a feed tank $(500 \mathrm{~L})$ to the required concentration. The waste water was then fed to the reactors using two peristaltic pumps (Watson Marlow Ltd).

During the experimental period, dissolved oxygen (DO) in the SAF was maintained above $4 \mathrm{mg} / \mathrm{L}$ (Dissolved Oxygen Meter, YSI MODEL 58). This was also to ensure that low dissolved oxygen was not restrictive.

During all experiments and prior to any shock loadings, synthetic wastewater was introduced at the inlet at the bottom of the reactor (Figure 1) at a flow rate of $0.00525 \mathrm{~L} \mathrm{~min}^{-1}$. The overall volume of synthetic feed in each of the reactors was $6.8 \mathrm{~L}$ and was kept constant by means of an overflow at the top of the reactor. Compressed air was supplied via air loop (Figure 1) at a flow rate of $1 \mathrm{Lmin}^{-1}$.

Under short-term shock loading conditions, the HRT was decreased from 22 hrs to 11 hrs by doubling the flow rate from original value of $0.00525 \mathrm{~L} \mathrm{~min}^{-1}$. The normal operation conditions were resumed after 12 hrs of short-term shock load. After the shock load, both reactors were operated under normal conditions and monitored for up to further 9 days after the HRT had reverted back to the original 22 hrs to observe recovery and any long-term effects of the shock load. The performance efficiency was tested by TOC, SS and ammonia,

During the organic shock loadings the hydraulic flow rate remained constant and the organic loading was increased by adding synthetic wastewater with double constituent concentrations to the model settled sewage (carried out 32 days after normal operation resumed from the hydraulic shock experiment). Results were analysed three days a week during this 39-day long-term organic shock loading.

\section{Table 1}

The composition of synthetic wastewater

\begin{tabular}{lc}
\hline Constituents & $\begin{array}{c}\text { Concentration } \\
(\mathrm{mg} / \mathrm{L})\end{array}$ \\
\hline Dextrin & 150 \\
\hline
\end{tabular}




\begin{tabular}{lc}
\hline Ammonium chloride & 130 \\
Yeast extract & 120 \\
Glucose & 100 \\
Soluble starch & 100 \\
Sodium carbonate & 150 \\
Detergent (commercial) & 10 \\
Sodium di-hydrogen orthophosphate & 100 \\
Potassium sulphate & 8.3 \\
\hline
\end{tabular}

\subsection{Analysis}

\subsubsection{Total Organic Carbon}

Rosemount Dohrmann Total Organic Carbon analyzer DC-190 was used to measure total carbon (TC) and inorganic carbon (IC), TOC is then calculated by subtraction. Sample volumes were $50 \mu \mathrm{L}$, injected by syringe. Average values and standard deviation were calculated by the instrument, only those values whose standard deviation was less than $1 \%$ were recorded and used. Analysis was carried out according to the standard methods [11]. The precision of this analysis is reported to be $\pm 5 \%$.

\subsubsection{Total Suspended Solids}

The analysis was carried out in accordance with standard technique [11]. The sample was well-mixed and then filtered through a weighed Whatman GF/C $(\varnothing 70 \mathrm{~mm}$ ) filter with a pore size of $1.2 \mu \mathrm{m} \pm 0.3$ $\mu \mathrm{m}$. The residue retained on the filter was dried in an oven at $105{ }^{\circ} \mathrm{C}$ for 1 hour, cooled in a dessicator and reweighed until the weight change on heating was less than $4 \%$ or $0.5 \mathrm{mg}$. The increase in weight of the filter is the total suspended solids when adjusted for the volume of sample. The precision of this analysis is reported to be $\pm 5 \%$.

\subsubsection{Ammonia Nitrogen}

Ammonia nitrogen was analysed using the Nessler's reagent method incorporated into the Palintest system. $10 \mathrm{mLs}$ of diluted samples to bring concentration of ammonia nitrogen between 0 and $10 \mathrm{mg} / \mathrm{L}$ were prepared based on experience from the synthetic sewage and steady state performance. The preprepared detection tablets Ammonia No.1 and 2 were added sequentially with mixing, and left for 10 
min. Then, samples were read using a Photometer (Palintest 5000) at the wavelength of $640 \mathrm{~nm}$. The precision of this analysis is reported to be $\pm 5 \%$ [11].

\section{Results and discussion}

\subsection{Short-Term Shock Loading}

The results from the transient hydraulic shock where hydraulic retention time (HRT) was reduced by half to an HRT of $11 \mathrm{hrs}$ for $12 \mathrm{hrs}$ are presented in Figures 2-4. The measurements of effluent concentration start from 24 hours after the transient loading. The results for TOC, SS, turbidity and ammonia removal for both SAFs with wool ${ }^{\circledR}$ and Kaldnes ${ }^{\circledR}$ media are shown in Figures 2 - 4.

\subsubsection{TOC removal}

The results show that after reducing the hydraulic retention time (HRT) by half in the shock study (Figure 2 at time 0), the SAFs were found to adapt themselves to the new feed concentration within 3 days. Thus, TOC of the effluent from the two bioreactors packed with wool ${ }^{\circledR}$ and Kaldnes ${ }^{\circledR}$ increased immediately from 4-6 mg/L to more than $10 \mathrm{mg} / \mathrm{L}$ (Figure 2 at time 1 day) after hydraulic shock loading. The reactors stabilised to this perturbation, and returned to steady operation within $72 \mathrm{hrs}$ after the cessation of the shock which was applied for half a day. It took at another 22 hours for the effect of the shock load to dissipate. After recovery, the maximum rate of TOC degradation efficiency was $95.63 \%$ and $95.72 \%$, respectively for the SAF with wool and Kaldnes. The rapid recovery of SAFs following the hydraulic shock loadings may be partly attributed to an adapted and active biomass that efficiently degraded the extra substrate delivered by the increased hydraulic load. The reason for the deterioration in performance during the hydraulic shock (day 1 and day 2) was likely to be due to channelling as a result of increased hydraulic pressure which resulted in less contact time between the biomass and the substrate. Nachaiyasit and Stuckey [7] in later work noticed decreasing the HRT from $20 \mathrm{hrs}$ to $10 \mathrm{hrs}$ increased the dead space to 39\%, and at short HRTs, channelling must have been occurring in the bed, and the bed properties enabled it to withstand hydraulic shocks well. This suggests lower removal performance of the system during the high hydraulic loadings as was seen to occur in the SAFs in this work could be due to the occurrence of dead zone and short circuiting. Substrate was simply washed through without being metabolised, probably because of channelling occurring in the biomass bed, or too short a contact time between the microorganisms and the substrate, or a combination of both. Biomass washout could explain the decrease in performance but this is not supported by the effluent SS results. 
The stability of SAFs to shocks compared to other processes was also noted by Lyssenko et al. [12]. In their experiments the shock was short-term shock $(30 \mathrm{~min}$ ) for six $5.23 \mathrm{~L}$ capacity biofilters (three trickling filters and three SAFs) filled with a media of specific surface area of $498.7 \mathrm{~m}^{2} / \mathrm{m}^{3}$ to study impact of total ammonia removal. It was found that SAFs were more efficient at ammonia removal than trickling filters. They believed SAFs are less sensitive to disturbances since unlike trickling filters there is some mixing and dilution of incoming wastewater inside SAFs. The biofilm of SAF in common with trickling filters protects the embedded bacteria from potentially harmful environmental conditions. Once favourable environmental conditions are resumed, the bacteria then regain their previous levels of degradation.

Fig. 2 - TOC Influent and effluent concentration of SAFs for short-term shock loading

The TOC effluent concentration and the recovery time of the SAF with Kaldnes ${ }^{\circledR}$ was similar to that of the SAF with wool.

\subsubsection{SS removal}

SS effluent concentration has not been noticeably affected with the decrease of HRT (Figure 3). There was slight increase in suspended solids concentration from $3 \mathrm{mg} / \mathrm{L}$ to $12 \mathrm{mg} /$ within the first day of the shock load for the reactor packed with wool. However, SS data fluctuated for both SAFs systems over the period of 42 days. The SS removal achieved was $100 \%$ and $98.67 \%$, respectively for the SAF with wool ${ }^{\circledR}$ and Kaldnes ${ }^{\circledR}$ while experiencing short-term shock loading. The results indicated that the flushing of solids was temporary and most of the extra solids from the increased load were retained.

The SS effluent concentration of the SAF with Kaldnes ${ }^{\circledR}$ was slightly higher than that of the SAF with wool as would be expected from the slightly lower overall performance at high hydraulic retention time in the SAF with Kaldnes ${ }^{\circledR}$ as described previously [13]. Borja and Banks [14] suggested that possible increase in suspended solids in the effluent could be attributed to the hydraulic shear, which may lead to biofilm detachment and an enhanced release of intermediates.

Nachaiyasit and Stuckey[7] emphasised (as have been discussed earlier) that at short HRTs, channelling must have been occurring in the bed, otherwise more biomass would have been washed from the reactor. In order to minimise the pressure drop through the bed, channelling occurred which resulted in lower contact between the biomass and the substrate. Substrate was simply washed through without being metabolised. This phenomenon was also observed by Grobicki and Stuckey[15] with 
short HRTs. This suggests lower SS removal performance of the system at high hydraulic loadings was due to hydraulic shear flushing out solids.

Fig. 3 - SS influent and effluent concentration of SAFs for short-term shock loading

\subsubsection{Ammonia removal}

The largest observed effect from the hydraulic shock was on ammonia removal as can be seen in Figure 4 this was from an extra 0.14 gram of ammonia was introduced.

After the short-term shock load, ammonia effluent concentrations from the two bioreactors packed with wool ${ }^{\circledR}$ and Kaldnes ${ }^{\circledR}$ rapidly increased from $0 \mathrm{mg} / \mathrm{L}$ to $17 \mathrm{mg} / \mathrm{L}$ and $25 \mathrm{mg} / \mathrm{L}$, respectively. The ammonia concentration from the SAF with wool rapidly decreased on the first day and was restored to pre-shock operation performance by the third day. The recovery period of the SAF with Kaldnes was apparently one day longer than that of the SAF with wool (Figure 4), which showed that the SAF with wool in common with the other data had an increased capacity to overcome hydraulic shock loading compared to the SAF with Kaldnes. Prior to the shock the average ammonia removal of the SAF with wool and Kaldnes was $99.1 \%$ and $98.7 \%$, respectively. During the shock this reduced to $60.61 \%$ and $42.42 \%$, and after the shock the maximum rate of ammonia removal efficiency was $99.8 \%$ and $99.7 \%$, which was similar to the average ammonia efficiency prior to the shock.

The rapid recovery of SAFs following the hydraulic shock loadings may be attributed the active and fixed nitrifiers that recovered efficiently and degraded the substrate throughout the experiment. It was unlikely there was sufficient time to have stimulated extra biomass growth.

In the current study, the ammonia degradation was apparently more sensitive than the other parameters, such as TOC and SS, confirming that nitrification was more vulnerable to the change of the experimental conditions. The reason may be attributed to the slow autotrophic growth of nitrification bacteria. They are poor competitors for space and oxygen, and hence they are only found in the deep interior of biofilms where they are easily overgrown by heterotrophs and oxygen concentration is low. Some studies have indicated that the heterotrophic microorganisms were accommodated in the lower parts of an upflow SAF where most of the organic conversion occurred. Nitrifiers were then able to occupy the upper parts where significant nitrification occurred [16,17]. This is much the pattern in nutrient removing activated sludge where separate chambers are designed for TOC removal, nitrification, phosphorus enrichment and denitrification [18]. The decrease of HRT may have weakened 
the activity of these nitrifiers by increasing competition from the heterotrophic microorganisms which inhibited mass transfer or the slower growth rate of the nitrifiers and reduced their ability to respond as quickly as the heterotrophic microorganisms, resulting in an increase of ammonia effluent concentration. In addition, lower removal performance of the system at high hydraulic loadings as that which occurred in the SAFs is due to the occurrence of dead zone and short circuiting [7, 15]. Furthermore with hydraulic surges, unattached biomass including nitrifiers could be washed out reducing performance.

Fig. 4 - Ammonia influent and effluent concentration of SAFs for short-term shock loading.

\subsection{Longer-Term Shock Loading}

During the longer-term organic shock loading, the feed organic loading rate (OLR) was doubled and lasted 40 days, during which TOC, SS and ammonia removal for both SAFs with wool ${ }^{\circledR}$ and Kaldnes ${ }^{\circledR}$ are presented in Figures 5 - 7. The $\mathrm{pH}$ value of influent and effluent was maintained between 7 and 8 , and the biomass was not critically stressed by the organic shock. The influent concentrations were increased to simulate potential accidents.

\subsubsection{TOC removal}

During the longer-term organic shock load, the effluent TOC concentration increased up to day 4 after which it began to readjust for both reactors (Figure 5). Even with this doubling of the load both SAF reactors were stable and reached a new steady state after approximately four HRT (10days). This time was sufficient to allow for increased microbial growth to respond to the shock load, after which the reactors returned to their stable performance. The new OLR was $0.22 \mathrm{kgTOC} / \mathrm{m}^{3} . \mathrm{d}$, twice that of the steady state operation. The average TOC removal efficiency was more than $95.25 \%$, even higher than that for the previous lower organic loading $(94.26 \%$ and $93.30 \%$ in reactors with wool and Kaldnes, respectively). This greater removal suggests the process was not fully loaded. First stage bioreactors for carbon removal might be expected to operate at $>1 \mathrm{kgBOD} / \mathrm{m}^{3}$.day but better performance at higher organic loadings are reported in this study compared to some previous other work on high levels of performance, for example Masse and Massé [8] and Nachaiyasit [4]. This was attributed to higher biomass concentrations and better mixing.

Stable operation continued to the end of the experiments (39 days), showing that the SAFs were resistant to organic shock loadings and that they maintained a similar TOC removal efficiency even 
when the loading was doubled. The difference in TOC removal between two SAFs packed with wool ${ }^{\circledR}$ and Kaldnes ${ }^{\circledR}$ was negligible (Figure 5). Nachaiyasit and Stuckey [7] reported on the effects of a doubled feed concentration in an anaerobic baffled reactor with 8 g/L COD for 20 days at an HRT of 20 hrs and found that the reactor was also able to adapt to double organic shock loadings and maintain the same removal efficiency. Masse and Massé [8] reported on larger organic shock loads (OLR was increased from 2.60 TCODg/L/day to 3.92 TCODg/L/day with a maximum 6.25 TCODg/L/day) to four SBRs and also reported a small and temporary effect on performance efficiency measured as Soluble Chemical Oxygen Demand (SCOD) and Volatile Fatty Acid (VFA) concentrations. Although Nachaiyasit [4] believed that during hydraulic shocks the rate of mass transfer of substrate into the biomass aggregates appeared to be the limiting factor. The major factor controlling the overall performance rate during organic shocks should be the kinetics of the uptake and consumption by the biomass. These shock loads can provide predictive insights into the likely limitation to reactor performance, in this case the balance between short circuiting and growth. This work is the first controlled experiments on shocks to SAF reactors and suggests different rate limiting factors for a model i.e. growth rate for organic shocks and mass transfer for hydraulic shocks. The stability of SAFs suggested that the biofilm in the SAFs played a more important role in resisting the organic shock loading than the type of media .

Fig. 5 - TOC influent and effluent concentration of SAFs for longer-term shock loading

\subsubsection{SS removal}

The good filter capacity of the wool fibre was reflected in the results from the organic shock loading (Figure 6). The SS effluent concentration from the SAF packed with wool ${ }^{\circledR}$ was very low and stable accept towards the end of the test. In contrast, the SS effluent concentration from the SAF with Kaldnes $^{\circledR}$ media fluctuated significantly (Figure 6), with SS value of up to more than $100 \mathrm{mg} / \mathrm{L}$. This was particularly pronounced at the beginning (days 1-14) during commissioning but was also evident towards the end of the experimental period (day 32 and day 39). The SD of the effluent SS values during the organic shock load were greater (9.11 and 50.32, respectively for the SAF with wool and Kaldnes) than the steady state period (3.66 and 14.11, respectively for the SAF with wool and Kaldnes) which suggested that solids retention was like ammonia ( in the hydraulic shocks) a potential indicator of instability. It seems most likely that under high SS loading, some influent SS could not be retained or biodegraded in the residence time in the SAF. The Kaldnes ${ }^{\circledR}$ became saturated with solids earlier than 
the wool reactor because of the lower filter surface area. The earlier results indicated hydrodynamic mixing was a factor. TOC was not affected in the same way (Figure 5) but solids lost from both the SAFs were increased. The soluble materials were removed but the biomass and filter capacity was unable to cope with the extra organic solids even though the hydraulic flow was unchanged. Therefore, despite the stable TOC results, the varied SS effluent concentration may reveal that solids retention becomes critical to performance hence the weaker performance of the SAF with Kaldnes ${ }^{\circledR}$ with fewer retention sites for solids. A survey of full-plants (large-scale common effluent treatment plants) in India [19] confirmed the SS removal performance could be affected even with $10 \%$ increased flow rate.

The SAF with wool had stable SS effluent (Figure 6) suggesting that neither the kinetics of the biomass or the hydrodynamic turbulence became limiting for the SAF packed with wool. In our studies hydraulic shocks were less detrimental as regards SS than organic loadings probably as a consequence of the well mixed conditions in the reactor.

Fig. 6 - SS influent and effluent concentration of SAFs for longer-term shock loading

\subsubsection{Ammonia removal}

The ammonia effluent concentration for both SAFs packed with wool ${ }^{\circledR}$ and Kaldnes $^{\circledR}$ media increased and reached their highest value after 4 days (Figure 7) after which there was recovery of ammonia effluent concentration. This stability was more disturbed for the reactor packed with Kaldnes when the temperature decreased below $12{ }^{\circ} \mathrm{C}$ on day 18 and thereafter (Figure 7) when the weather turned cold due to seasonal changes and the reactors were in an unheated pilot plant room. The effect of temperature on the slow growing nitrifying biomass has been well reported, i.e. the reaction is approximately halved for every $10{ }^{\circ} \mathrm{C}$ drop in temperature [20].

The ammonia effluent concentration from the SAF with Kaldnes ${ }^{\circledR}$ fluctuated more than that from wool $^{\circledR}$ reactor during most of the organic shock loading. It was not as stable as the SAF with wool but neither SAF were able to tolerate twice the ammonia shock loading during the 39 days of the trial. Thus, the organic shock loading caused a disturbance in ammonia removal suggesting that insufficient biomass had grown to compensate even though the trial lasted 3-4 times the reported growth rate. The growth rate of nitrifying bacteria is thought to be around 10 days. The slower growth rate of the nitrifying bacteria makes them vulnerable to competition from the heterotrophic population [13].

Fig. 7 - Ammonia influent and effluent concentration of SAFs for longer-term shock loading. 


\subsubsection{Effect of temperature on TOC, SS and Ammonia removal}

SAFs are reported as less subject to variance in environmental temperature compared to activated sludge $[21,22]$.

During the experiments temperature varied from $15{ }^{0} \mathrm{C}$ to $21{ }^{0} \mathrm{C}$ for the hydraulic shock and from $11{ }^{0} \mathrm{C}$ to $20.5{ }^{0} \mathrm{C}$ for the organic shock loadings.

There was no concise correlation between temperature and TOC, SS and ammonia removal between. Some trends on the SS removal can be detected. Thus, between 14 and $17{ }^{0} \mathrm{C}$ the average SS removal efficiency of the SAFs with wool and Kaldnes was $97 \%$ and $92 \%$, respectively. Slightly better SS removal efficiency was achieved between $17-20.5{ }^{\circ} \mathrm{C}$, resulting in average value of $97.5 \%$ and $95.5 \%$ for SAFs with wool and Kaldnes, respectively. A greater solids production from the wool was expected because breakdown of the wool was anticipated but this must have been biodegraded.

\section{Conclusions}

1) In this work on two different media measured parameters, TOC, SS and ammonia were affected similarly by transient hydraulic shock loads on SAF systems (packed with wool or Kaldnes). The ammonia removal was apparently more sensitive than the other parameters, which was attributed to the slow growth of nitrification bacteria, which are poor competitors for space and substrate.

2) During the short-term hydraulic shock study, both the wool and Kaldnes SAF were found to have returned to normal operation within $72 \mathrm{hrs}$ after the cessation of the shock which lasted half a day. Overall, the SAF with wool had better capacity to overcome hydraulic and organic shocks than the SAF with Kaldnes. The maximum rate of TOC degradation efficiency was $95.63 \%$ and $95.72 \%$ and the maximum rate of ammonia removal efficiency was $99.8 \%$ and $99.69 \%$, respectively for the SAF with woo ${ }^{1 \circledR}$ and Kaldnes ${ }^{\circledR \circledR}$ media. This suggests that mass transfer and biomass growth were not impaired there was no evidence of biomass loss through washout. The rapid recovery suggested the SAFs were less sensitive to these disturbances than trickling filters (from the literature).

The stability of SAFs showed the biofilm and mixing conditions in the SAFs played an 
important role in resisting the organic shock load.

3) During the longer-term organic shock loading, the TOC effluent concentration was effected for 4 days after which it was able to readjust. After the reactors returned to its stable state, the average TOC removal efficiency was more than $95 \%$ indistinguishable to before the shock and stable operation continued to the end of the experiments (39 days). The difference in TOC removal between two SAFs packed with wool ${ }^{\circledR}$ and Kaldnes ${ }^{\circledR}$ was negligible.

4) The good filter capacity of the wool fibre was reflected in the SS effluent concentration during the organic shock which was low (less than $20 \mathrm{mg} / \mathrm{L}$ ), but then deteriorated 30 days after the shock suggesting this might be the total biomass turnover time rather than just the growth rate. end of the The SS effluent concentrations from the SAF packed with Kaldnes fluctuated significantly indicating less successful retention of the greater biomass activity. It was proposed that the solids accumulation in the wool took 30 days to reach saturation compared to just a few days in the large pore spaced kaldnes. In our studies hydraulic shocks were less detrimental than organic loads to solids retention suggesting well mixed conditions in the reactor.

5) With a doubling of the organic load, the reactors also responded rapidly to the shock but were less resistant to the increased ammonia than either to the solids or TOC, following the longerterm organic shock load. Stability was not achieved at the 3-4 times the growth rates of the nitrifyers residual ammonia were above the EU standards. This confirms previous work steady loads or loads less than $0.2 \mathrm{~kg} / \mathrm{m}^{3}$ day from multistage treatment are necessary to reach the standard .

\section{Acknowledgments}

The authors are grateful to Loughborough University and De Montfort University for the provision of facilities.

\section{References}


1. N. Cicek, A review of membrane bioreactors and their potential application in the treatment of agricultural wastewater, Can. Biosys. Eng. 45 (2003) 637-646.

2. A.K.B. Amorim, M. Zaiat, E. Foresti, Performance and stability of anaerobic fixed bed reactor subjected to progressive increasing concentrations of influent organic matter and organic shock loads, J.Environ. Management, 76 (2005) 319-325.

3. A.F.Jr. Gaudy and E.T. Gaudy, Microbiology for Environmental Scientists and Engineers, McGrawHill, New York, 1980.

4. S. Nachaiyasit, The effect of process parameters on reactor performance in an anaerobic baffled reactor, $\mathrm{PhD}$ thesis (1995), Imperial College, London.

5. F.R. Mora, G. Ferrara De Giner, A.R. Andara, J.L. Esteban, Effect of organic carbon shock loading on endogenous denitrification in sequential batch reactors, Bioresour. Technol., 88 (2003) 215-219.

6. T.K. George, J.R. Gaudy, Response of completely mixed systems to hydraulic shock loads, ASCE EE Division (1973) 597-606.

7. S. Nachaiyasit and D.C. Stuckey, The effect of shock loads on the performance of an anaerobic baffled reactor (ABR). 2. Step and transient hydraulic shocks at constant feed strength, Water Res. 31 (1997b) 2747-2754.

8. L. Masse and D. I. Masse, Effect of soluble organic, particulate organic, and hydraulic shock loads on anaerobic sequencing batch reactors treating slaughterhouse wastewater at $20^{\circ} \mathrm{C}$, Process Biochem. 40 (2005) 1225-1232.

9. A.D. Cannon, K.R. Gray, A.J. Biddlestone, K. Thayanithy, Pilot-scale development of a bioreactor for the treatment of dairy dirty water, J. Agric. Eng. Res. 77 (2000) 327-334.

10. S. Phanapavudhikul, The effect of temperature on activated sludge plant operation, PhD thesis (1978), Loughborough University of Technology.

11. APHA, AWWA \&. WEF, Standard Methods for the Examination of Water and Wastewater, twentieth ed. American Public Health Association/American Water Works Association/Water Environment Federation (1998), Washington DC, USA.

12. C. Lyssenko and F. Wheaton, Impact of rapid impulse operating disturbances on ammonia removal by trickling and submerged-upflow biofilters for intensive recirculating aquaculture, Aquacult. Eng. 35 (2006) 38-50.

13. B. Hu, Sewage Treatment by Bioreactor Using a Novel Wool Fleece Media, PhD thesis (2008). Loughborough University, 130-141.

14. R. Borja and C.J. Banks, Kinetics of an anaerobic fluidized bed system used for the purification of fruit processing wastewater, Chem. Eng. J. 54 (1994) B25-B32. 
15. A.M.W. Grobicki and D.C. Stuckey, Performance of the anaerobic baffled reactor under steady state and shock loading conditions. Biotechnol. Bioeng. 37 (1991) 344-355.

16. O. Wanner and W. Gujer, Competition in biofilms, Wat. Sci. Tech. 17 (1985) 27-44.

17. D.S. Parker and T. Richards, Nitrification in trickling filters, Journal WPCF 58 (1986) 896-902.

18. A.G. Boon, V.K. Thomas, Intensification of the activated-sludge process (Abridged), Water Env. J. 12 (1998) 357-367.

19. G.R. Pophali, S.N. Kaul, S. Mathur, Influence of hydraulic shock loads and TDS on the performance of large-scale CETPs treating textile effluents in India, Water Res. 37 (2003) 353-361

20. C.P.L. Grady, H.C. Lim, Biological Wastewater Treatment, Marcel Dekker, New York (1980).

21. B, Rusten, Wastewater treatment with aerated submerged biological filters, Journal WPCF (1984) 424-431.

22. P.S. Golla, A.J. Lin, Cold temperature nitrification using captor process, 46 Purdue Industrial Waste Conference Proceedings (1992) 631-640. 